\title{
Composiciones familiares y configuraciones matrimoniales en redes genealógicas indígenas del oriente jujeño, Siglo XIX
}

\section{Family compositions and marriage configurations on aboriginal genealogical networks from eastern Jujuy, XIXth. Century}

\author{
Juan Pablo Ferreiro ${ }^{1}$ \\ En memoria de Rodolfo Urbano Freyre y de su proyecto por un nacimiento sin violencia, \\ del cual orgullosamente formamos parte.
}

\section{El mapa no es el territorio. Gregory Bateson}

\begin{abstract}
Resumen
Gregory Bateson propone como objeto y fin de sus reflexiones en Espiritu y Naturaleza la noción de "pauta que conecta", a través de preguntas tales como ¿cuál es la pauta que conecta a todas las criaturas vivientes? Hemos escogido, como objeto de nuestro análisis, en cambio, una dimensión fractal de aquella propuesta, restringida a los vínculos desarrollados en los campos nucleares de la reproducción sociocultural. Nuestro interés es reconocer y analizar las configuraciones de algunos vínculos de parentesco y la ocupación que hace de una región delimitada espacial y temporalmente un conjunto discreto de familias campesinas indígenas. Esto es, los criterios, regularidades y tendencias que exhiben estos conjuntos en sus aspectos más básicos y primarios: aquellos que estructuran, regulan y distribuyen la reproducción social a través de la organización doméstica y las alianzas matrimoniales. Los materiales escogidos para tal tarea provienen de una genealogía reconstruida de conjuntos parentales indígenas rurales del siglo XIX. Nuestra estrategia analítica se basa en el Análisis de Redes de Parentesco y la Teoría de Grafos.
\end{abstract}

Palabras claves: parentesco andino, genealogía, redes sociales, Antropología Histórica, circuitos matrimoniales.

\begin{abstract}
Gregory Bateson proposes as the goal of his reflections in Mind and Nature the notion of "the pattern which connects" through questions such as what is the pattern which connects all living creatures? We have chosen as the object of our analysis, however, a fractal dimension of that, restricted to the links developed at the core of socio-cultural reproduction. Our interest is to recognize and analyze social configurations that develop kinship links and his occupation of a spatial and temporarily delimited region by a discrete set of indigenous peasant families. That is, the criteria, regularities and trends shown by these sets in their most basic and primary aspects: those that structures regulate and distribute the social reproduction through domestic organization and marriage alliances. The materials chosen for this task are from peasants indigenous reconstructed genealogy kin sets from nineteenth century. Our analytical strategy is based on Kinship Network Analysis and Graph Theory.
\end{abstract}

Keywords: Andean kinship, genealogy, social networks, Historical Anthropology, Matrimonial circuits.

Recibido: 6 abril 2016. Aceptado: 19 septiembre 2016

1 UE CISOR-CONICET/Universidad Nacional de Jujuy, El Naranjero 384, 4600 San Salvador de Jujuy. ARGENTINA. Email: tresaguilhones@gmail.com 


\section{Introducción}

El presente trabajo es el producto de una línea de investigación actualmente en curso, algunos de cuyos datos han sido ya publicados (Ferreiro, 2013, 2104; Ferreiro y Fernández, 2013). En el primero de los artículos referidos, denominado "Compadrazgo y dinámica reticular en Valle Grande, Jujuy”, analicé la dinámica y estructura del sistema de compadrazgo de la zona de Valle Grande durante el siglo XIX, utilizando, entre otras, información referida al frente de parentesco Apaza -que es el sujeto principal del presente esfuerzo- y al uso que los miembros de diversos conjuntos familiares dieron a estos vínculos de parentesco simbólico, y cómo tal utilización les permitió acceder de manera diferenciada a zonas y territorios en los cuales no habían establecido lazos nupciales previamente. En el trabajo titulado "Los apellidos, la organización familiar y los circuitos productivos como determinantes de la cotidianeidad en el oriente jujeño, siglo XIX", exploré los límites de lo cotidiano a partir de un enfoque estructural que me permitió identificar y describir los circuitos anuales que detallaban los movimientos territoriales de estos pastores trashumantes, a través de la actividad de los distintos frentes de parentesco y conjuntos familiares en los que se organizaban -incluidos los Apaza-, así como los ciclos a los que tendían su socialización y reproducción. En el último texto referido, "Nupcialidad, compadrazgo y endogamia en las Yungas de Jujuy (Noroeste de Argentina) durante la primera mitad del siglo XIX", optamos por analizar en conjunto los vínculos matrimoniales, las configuraciones de organización doméstica y parental y los lazos de compadrazgo de toda la población de la región vallegrandina, dentro de la cual se encuentran comprendidos los miembros del frente de parentesco Apaza. Dicha estrategia de pesquisa nos permitió establecer, a partir de una perspectiva estructural microanalítica, la dinámica de ocupación territorial de la región de Valle Grande durante el siglo XIX, su similitud configuracional con organizaciones parentales tradicionales andinas -aún en ausencia de sus denominaciones categoriales-, y explicar las altas tasas de endogamia como dispositivos relacionales.

De esta línea de investigación, entonces, han surgido, como resultados pertinentes a nuestros actuales fines, dos grandes cuerpos genealógicos. El primero de ellos, ya analizado y presentado parcialmente, sirve de plataforma metodológica al esfuerzo que hoy proponemos como su continuación, extensión y cotejo (Ferreiro, 2016). En dicho trabajo, ya publicado y titulado "De barro somos... Ciclos familiares y genealogía en el poblamiento del oriente jujeńo del XIX", propusimos y justificamos como estrategia para el análisis de los vínculos de parentesco un cambio metodológico que plantea un juego de articulación de escalas -entre el desempeño individual y el del pequeño grupo- y el reemplazo del esquema genealógico tradicional por otro que, a partir de él, nos permitiese reconstruir de manera eficaz la composición y dinámica de un cuerpo parental discreto a través del tiempo y el espacio, el del frente de parentesco Mamaní.

Este mismo esfuerzo nos permitió constituir otro gran conjunto genealógico, inédito $y$, por su misma naturaleza, aún en construcción, el del frente de parentesco Apaza, cuyas composiciones familiares y configuraciones matrimoniales analizaremos en este trabajo.

Este conjunto parental se asentó, principalmente, en la zona del oriente jujeño, ocupando diversos pisos ecoambientales que van desde las selvas húmedas de las yungas en el meridional valle de $\mathrm{La}$ Candelaria (1000 msnm) hasta los valles altos de la zona de Santa Ana (4700 msnm), en el extremo septentrional del actual departamento de Valle Grande, provincia de Jujuy (ver Figura 1). En este marco sus integrantes desarrollaron sus actividades fundamentalmente ganaderas, de horticultura de autoconsumo y recolección a partir de un patrón trashumante estacional, con control familiar de la producción sobre un territorio política y socialmente fragmentado, el cual compartían -y aún lo hacen- con otros grupos. La zona descrita comprende un sector marginal respecto de los principales ejes provinciales desde la época colonial, en la que era considerada la frontera del enemigo chaqueño y como tal fue objeto de expediciones militares y de colonización -habitualmente frustradas-, ya que constituyó durante siglos el área de contacto entre los grupos de agricultores y pastores de altura con los horticultores de secano y cazadores-recolectores del piedemonte chaqueño y las tierras bajas. A pesar de que la arqueología de la zona es todavía incipiente y poco conocida, queda claro que el área presenta 


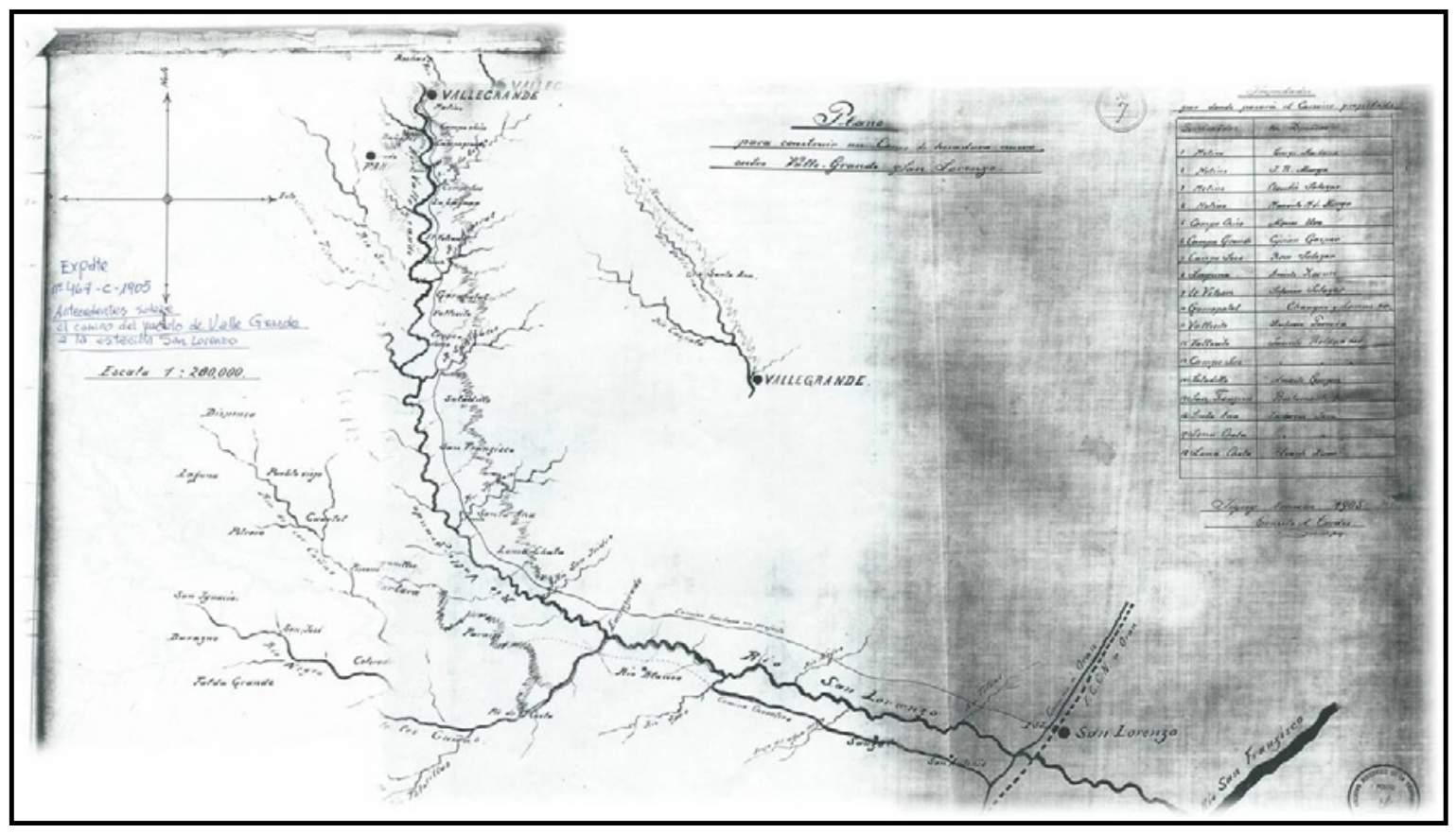

Figura 1. Mapa de Valle Grande (1905). Expediente 467-C-1905, Archivo Histórico de la provincia de Jujuy.

una larga ocupación anterior a la conquista espańola, visible aún en los numerosos vestigios materiales, de los cuales las diversas travesías locales del Q'apaq Nan son elocuente evidencia, sobre todo en el sector septentrional del valle. ${ }^{2}$

2 Las relaciones entre tierras altas y tierras bajas se reflejan particularmente en el folclore vallegrandense, tanto en instrumentos típicos de la región chaqueña, como el trompo, característicamente wichí -construidos por un artesano en Santa Ana-; como en las celebraciones carnavalescas cuyas danzas más típicas tienen similar estructura rítmica y coreográfica que la danza guaranítica pin-pin de las tierras bajas. Leyendas y personajes míticos locales también recuerdan los tradicionales entre guaraníes y wichís del piedemonte y ramal jujeńo. Por otra parte, esta circunstancia remite a una diferenciación emic portadora de identidades locales, la diferenciación entre la gente "de arriba" y la gente "de abajo", asociados, unos a "lo coya", como condensación de la población de altura; y por otro lado, lo "ocloya", vinculado a la gente de la zona baja. Debemos señalar que la Secretaría de Cultura de la Provincia de Jujuy, hasta 2015, incluyó la zona en un proceso de recopilación del patrimonio material e inmaterial, cuyo eje fue puesto en el relevamiento de los distintos fragmentos del denominado "camino inca" de la zona. Para una relación representativa, aunque no exhaustiva, de la información etnoarqueológica sobre la región remitimos a las siguientes obras: Nielsen, A. (1989); De Feo, C. y
Para su mejor ubicación ofrecemos un mapa caminero manuscrito levantado a principios del siglo XX y que identifica la región y trayectos principales sobre los cuales vienen discurriendo los pasos de los integrantes de este conjunto de familias desde comienzos del siglo XIX. Este camino, cuyo trazado muestra el mapa, fue el primer emprendimiento carretero estatal para la zona y, en líneas generales, es la base de la actual traza caminera que hoy llega hasta Valle Colorado desde la localidad de Calilegua, en el piedemonte oriental.

Pero antes de entrar en el tema considero necesario hacer algunas aclaraciones y precisiones sobre la naturaleza de los materiales, las herramientas y las perspectivas que utilizaré.

En trabajos anteriores hemos podido establecer que la zona septentrional de Valle Grande ya estaba poblada a fines del siglo XVII, a partir de la estancia ganadera dada en merced real a Martín de Goyechea. En aquella ocasión solo se registraban como núcleos poblacionales a Caspalá, Alto Calilegua

Fernández, A. (1998); Ferreiro, J. P. (1994); Fumagalli, M. (1995); Nielsen, A. (2003); Sánchez, S. y Sica, G. (1990); Salas, A. M.(1992). 
y Yala de Monte Carmelo, aún existentes. A principios del siglo XIX fue repoblada por contingentes provenientes de los valles del norte, del sector septentrional de la Quebrada de Humahuaca y de las altiplanicies limítrofes con el entonces así denominado Alto Perú. De estos grupos se nutrió el FP Apaza. Durante el curso de los siglos XVIII y primera mitad del XIX, y tras atravesar tanto los avatares de las guerras de independencia, conflictos civiles y alternativas legales con cambios de propiedad, este territorio fue fragmentado en hasta cuatro dominios individuales, siendo la denominada Finca Valle, del propietario Rufino Valle, la más extensa de todas. En la década de 1850 éstas compusieron lo que fue reconocido como departamento Valle Grande. En 1887, desaparecida la viuda y sucesora del Sr. Rufino Valle, el estado provincial procedió a disolver la gran propiedad mediante un proceso de venta de tierras a sus ocupantes tradicionales, quienes eran arrendatarios indígenas en su casi absoluta mayoría y que las disponían de manera colectiva. Esta gran unidad proveyó al departamento la casi totalidad de su actual jurisdicción, el cual, a partir de ese proceso, se caracterizó por la composición de pequeñas y medianas huertas de extensión variable en un espacio fragmentado y multiforme, en manos de propietarios nativos y bajo un régimen formal de propiedad individual que contemplaba la existencia de territorios de uso común. La información de la que disponemos sugiere que, ayer como hoy, el patrimonio tendió a transmitirse por vía paralela; mientras las tierras y el ganado mayor discurrieron a través de una sucesión patrilineal y masculina, el ganado menor lo hizo por vía matrilineal y femenina. Si bien esto no puede ser entendido como una regla, en el sentido que la antropología clásica otorgaba a los mecanismos de herencia -ya que se pueden observar excepciones- habitualmente, sobre todo cuando el legatario territorial era una propietaria, sí se presenta como una disposición recurrente y mayoritaria en nuestra prospección etnográfica.

Tal población se mantuvo demográficamente estable hasta la actualidad, sin superar la barrera de los 3 mil habitantes durante el siglo XIX, dispuestos en un número variable de alrededor de diez poblados al día de hoy (Ferreiro, 2016).

\section{Perspectivas y herramientas}

Siguiendo la recomendación de E. E. Evans-Pritchard, que la antropología debe estudiar fundamentalmente problemas y no comunidades, fue que fijamos nuestro punto de impulso en una idea-guía del biólogo y antropólogo británico Gregory Bateson; aquella a la que alude con "la pauta que conecta", cuya elucidación es un tema central de su ya clásica obra Espiritu y Naturaleza (1979). A través de ella este autor argumenta su respuesta a preguntas tales como ¿Cuál es la pauta que conecta a todas las criaturas vivientes? (Bateson, 1979, p. 18). Siguiendo a este autor, afirmamos que constituye el punto de impulso porque entendemos esta pregunta como una metapauta que informa acerca de los patrones redundantes y relaciones similares que conectan y distinguen los distintos fenómenos, rasgos, tramas y ámbitos en los cuales aquella pauta se desenvuelve y les otorga una consistencia, un tono característico. Tales relaciones, mucho más acotadas en su interés y esfera de acción, actúan como una suerte de reducción fractal de tal problema. Nuestro interés se concentra y reduce, en este último sentido, al ámbito de la organización de la reproducción social en un espacio y una sociedad dados. De tal modo que lo que planteamos como objeto de nuestra atención son aquellos patrones redundantes, aquellas relaciones similares entre partes que establecen entre sí una "danza interactiva" que está sujeta a condiciones y estrategias. ${ }^{3}$ Tales condiciones son, más bien, aquello que evoluciona y se transforma a partir de su aplicación estratégica; en un sentido similar a lo que Claude Lévi-Strauss (1969) planteara acerca de las reglas de parentesco como la constricción de un juego, o de la performance de una "danza" en función de un conjunto de disposiciones, que implican pericias, facultades y circunstancias, y de un resultado.

Nuestro interés es reconocer estos dispositivos que articulan y habilitan u obturan una configuración particular de los vínculos de parentesco, los matri-

3 "En verdad, para comenzar a pensar en la pauta que conecta lo correcto es considerarla primordialmente (cualquiera sea el significado de esta palabra) como una danza de partes interactuantes, y solo secundariamente fijada por diversas clases de límites físicos y por los límites que imponen de manera característica los organismos" (Bateson, 1979, p. 23). 
monios o uniones conyugales, en una región delimitada espacial y temporalmente. En lugar de buscar identificaciones apriorísticas que caractericen su estructura y dinámica, proponemos el ejercicio inverso. Ver, reconocer y definir qué pauta o pautas despliega en el espacio/tiempo un conjunto de grupos sociales discretos y su desarrollo, qué propiedades o atributos presentan que permitan caracterizar las pautas. Esto es, qué criterios, regularidades o tendencias exhiben estos grupos en sus organizaciones más básicas y primarias: aquellas que organizan, regulan y distribuyen la reproducción social. Esta última presenta algunas dimensiones esenciales al desplegarse en el tiempo y en el espacio, articulando el desempeño individual de los miembros de uno o más grupos, con las tendencias colectivas que tales organizaciones desarrollan; lo cual discurre a lo largo de un eje vertical temporal, recuperable parcialmente a través del ejercicio genealógico. Pero también integra grupos distintos sobre un eje de vinculación horizontal -el mismo de las redes egocentradas- en el marco del desarrollo de las sociabilidades, siendo ésta la auténtica causa eficiente de expansión de la trama social.

Estas pesquisas se aplicaron sobre un conjunto diverso de materiales documentales, de distinta procedencia y naturaleza. Por una parte, un conjunto de más de 1300 registros individuales procedentes de libros parroquiales de la Prelatura de Humahuaca, a los que se agregan censos provinciales y nacionales, padrones y otros listados nominativos del Archivo Histórico de la Provincia de Jujuy y del repositorio de la Iglesia de Jesucristo de los Santos de los Últimos Días (mormones); de la Dirección General de Inmuebles de la Provincia de Jujuy y expedientes judiciales alojados en el Archivo de Tribunales de la Provincia de Jujuy, cubriendo el período que abarca desde 1801 a 1890. Por otra parte, se añadieron genealogías cortas construidas sobre la base de testimonios orales procedentes de la zona alta de Valle Grande, más específicamente de la localidad de Santa Ana, y que cubren el período 1930 hasta la actualidad y procedentes del trabajo de campo etnográfico.

Este relativamente voluminoso material dista de poseer las mismas características e información. Lejos de ello, el trabajo más arduo consistió, sin duda alguna, en un proceso de estandarización que permitiese su cotejo y comparación. Precisamente, estas actividades fueron las que de algún modo impusieron una determinada metodología de trabajo y unas herramientas específicas que permitiesen establecer criterios de unidad formal, a fines analíticos y comparativos, y habilitasen la posibilidad de recuperar, aun fragmentariamente, los procesos lógicos de categorización, recopilación y registro originales de los materiales procedentes de censos y empadronamientos. Esto es, los criterios de clasificación y orden a los que esta información fue sometida $y$, consecuentemente, presentada. De la lectura atenta de los listados, censos y padrones y de su cruce con la -escasa- información existente sobre los mecanismos, circunstancias y personajes que llevaron a cabo los registros, hemos podido deducir que, en lo fundamental, las fuentes parecen haber sido recopiladas siguiendo algunos pocos objetivos generales. Obtener información confiable que permitiese el control espiritual de poblaciones integrantes de un conjunto de subparroquias rurales del curato de Humahuaca; obtener información general sobre la población de una zona aislada y, en particular, sobre la disponibilidad de su población masculina a una potencial leva militar; obtener información sobre la población asentada en territorios de potencial conflicto fiscal y catastral; obtener información sobre la población general del territorio nacional.

Todo lo anterior, leído desde una consideración crítica y consciente de las limitaciones de la tradicional práctica genealógica, nos condujo a privilegiar el análisis de procesos en pequeña y mediana escala, lo que en análisis de redes se denomina habitualmente, nivel meso; esto es, allí donde es posible articular el desempeño individual, que es fundamentalmente el registrado por las fuentes escritas y sobre todo las orales, con la acción de los pequeños grupos o conjuntos parentales en los que se insertan y desarrollan tales performances (Ferrand, 2003). Precisamente, una categoría que da cuenta de tal articulación y que permite ligar estas acciones con una dinámica familiar de tipo parentela (kindred) es la que provee, y en consecuencia adoptamos, la noción de "frente de parentesco" propuesta por Giovanni Lévi (1989), a partir de la cual es posible reconocer un conjunto discreto de individuos y apellidos vinculados a un patronímico demográfica, social y políticamente central que sirve de aglutinante colectivo y que concentra las actividades de transmisión patrimonial y 
reciprocidad laboral, monetaria, político-social, etcétera. El dispositivo central que liga a ese conjunto, o mejor dicho, del cual ese conjunto resulta su expresión corporativa, es la unión de un principio filiatorio, a través del cual se ligan en el tiempo diversas generaciones sucesivas y sus patrimonios; con un principio de alianza o asociación que constituye la auténtica clave de la expansión de la trama social, al poner en contacto íntimo y potencialmente reproductivo, grupos familiares diversos mediante uniones conyugales más o menos institucionalizadas, desde las cuales se fundan nuevas unidades discretas.

Todas estas consideraciones son las que permiten articular el desempeño individual con el colectivo a través de la identificación de las tendencias en las que aquellas acciones se insertan en movimientos más vastos que les dan sentido y una dirección histórica, social y culturalmente reconocibles. Este enlace del acontecimiento con lo estructural de nivel meso requiere, más que de un cotejo de medidas representativas, de un análisis de los diversos y complejos procesos y subprocesos que en esas relaciones se despliegan. Tal panorama reclama una metodología y unas herramientas que puedan dar cuenta de estas situaciones en términos de su estandarización, ordenamiento, presentación y análisis. Una primera estrategia escogida, que a nuestro juicio se ha revelado particularmente apta a tales fines, ha sido la adopción de la perspectiva estructural brindada por el denominado Análisis de Redes Sociales (ARS). Ésta, a través de la lógica matricial y de las posibilidades analíticas que conlleva, habilita el análisis gráfico de vínculos parentales al interior de las genealogías estudiadas a partir de su vectorización y valoración atributiva en un espacio topológico delimitado. Esta disposición busca representar ese fragmento del espacio cultural y parental, discontinuo y por definición incompleto que constituye la trama en la que las generaciones se ligan unas con otras a través del espacio, el tiempo y las prácticas. En este punto, la noción de red simula modélicamente tales relaciones siguiendo un conjunto de lazos de valor ponderado, establecidos al interior de un conjunto discreto de nodos. ${ }^{4}$

4 En este punto adquiere relevancia la cita de Bateson con la que comenzamos el artículo. Con ella aludimos a que el modelo NO puede confundirse con la realidad bajo
Las herramientas técnicas analíticas cuyo uso hemos privilegiado a tales fines han sido el software libre PAJEK y el paquete comercial UCINET v.6.0. ${ }^{5}$

Una segunda estrategia se concentró en el desarrollo de una perspectiva alternativa y crítica de la tradicional notación de parentesco, la cual forma parte del núcleo de la práctica genealógica, basada en la propuesta metodológica elaborada por Laurent $\mathrm{Ba}$ rry (2004), y el uso de un paquete analítico de él derivado, el software PUCK. ${ }^{6}$ La propuesta de este autor, denominada notación posicional, viene a paliar algunos problemas mayores que presenta la notación genealógica tradicional en Antropología vinculados a su origen en un lenguaje "natural", en este caso, el inglés.

En primer lugar, esta última tiende a confundir las similitudes estructurales y las propiedades particulares de las relaciones de parentesco. El sistema tradicional, por otra parte, es bastante poco "intuitivo" en la expresión de los vínculos parentales que describe y, más allá de los casos más simples, precisa de un sustento gráfico que lo facilite. Además, al no reconocer el ancestro apical se dificulta identificar sin un soporte gráfico el grado de vinculación existente en la generación antecedente involucrada, con lo cual fenómenos tales como los reenlaces endogámicos, que tienen un alcance decisivo en los vínculos descenden-

ninguna circunstancia - la que, por otra parte, es inaccesible por su propia temporalidad-, sino que solo constituye una aproximación simplificada y fragmentaria, ordenada de acuerdo a algunos vectores privilegiados, a partir de los cuales aspira a convertirse en guía analítica específica.

5 Andrej Mrvar and Vladimir Batagelj, November 1996 - September 2013, Pajek 643.13 Copyright (C) 1996, http://pajek.imfm.si/. Borgatti, S. P.; Everett, M.G., Freeman, L. C., 2002, Ucinet 6 for Windows: Software for Social Networks Analysis, Analytic Technologies, Harvard.

6 Este programa también ha sido utilizado en Ferreiro (2016). Klaus Hamberger, Christian Momon, Edoardo Savoia et Telmo Menezes, 2007, Puck 1.2.46 November 11 2014; Program for the Use and Computation of Kinship Data; (c) Groupe de Recherche TIP (Traitement Informatique de la Parenté), Centre National de Recherche Scientifique, Paris, Distribué sous licence CeCILL version 2 (http://www.cecill.info/), http:// www.kintip.net/ 
tes, se ven obscurecidos. ${ }^{7}$ A lo que habría que añadir una economía expositiva que dificulta y entorpece la comprensión inmediata de los vínculos, como es el número excesivo de códigos identificadores de roles de parentesco, que son alrededor de doce, contra solo tres símbolos que propone la notación alternativa. La notación posicional, en resumen, consiste en que

\section{[...] una relación de parentesco es representada} aqui por una secuencia de letras que especifican vértices rotulados (género) y signos diacriticos, los cuales indican la presencia de una arista matrimonial (el punto "."), y la posición apical de un vértice (los paréntesis "()"). Todas las letras no separadas por un punto representan vértices conectados por arcos, los vértices en posición "apical" (p.e. vértices que no poseen como vecino a un niño) son puestos entre paréntesis $y$, por convención, todos los arcos a la izquierda de un vértice apical presentan dirección ascendente, mientras que los arcos ubicados a su derecha tienen dirección descendente, $y$ los puntos matrimoniales implican un cambio en la dirección. ${ }^{8}$

Este último enfoque destaca con claridad que una primera pauta a considerar, de importancia central, es la unión matrimonial que permite articular entre diversas líneas de descendencia familiares, ya que

\section{...la manera en la que una estructura social} puede ser modificada por un matrimonio potencial afecta la posibilidad de ocurrencia de tal matrimonio, ya sea de modo explícito (a través de reglas matrimoniales y prohibiciones de incesto), implicito (en virtud de preferencias o estrategias), directamente (tomando en cuenta lazos parentales entre esposos potenciales), o indirectamente (tomando en cuenta otros factores que, a su vez, están correlacionados con el parentesco). Muchas de estas consideraciones que afectan positiva o negativamente las elecciones matrimoniales pueden expresarse como cadenas de parentesco más o menos complejas y/o rela-

7 Barry, Laurent (2004).

8 Hamberger, Houseman, White, 2011, pp. 538-539 (trad. pers.). ciones matrimoniales entre esposos potenciales. Tales cadenas, si están "cerradas" por un lazo matrimonial, pueden transformarse en nuevos circuitos relacionales dentro de la red de parentesco. Tales circuitos, cuando están hechos completamente de vinculos parentales y nupciales, son denominados circuitos matrimoniales. La conducta autoorganizada de una red de parentesco puede, entonces, en gran parte ser entendida como una tendencia hacia la formación local de algún tipo de circuito matrimonial y/o la aversión a la formación de otros. ${ }^{9}$

En otras palabras, cada uno de estos circuitos, cuyo análisis expone la notación posicional, representa un tipo particular y concreto de matrimonio dentro de la red. La frecuencia de un tipo no habla inmediatamente de una preferencia o norma, pero sí resulta ser una función de una configuración de opciones, posiciones y relaciones previas. En este sentido, entenderemos el circuito matrimonial como una cadena donde los extremos coinciden y que posee, por lo menos, un lazo matrimonial. ${ }^{10}$ Dos circuitos son del mismo tipo -si y solo si pueden conmutarse uno en otro-, preservando el género de los agentes y la direccionalidad del vínculo, por lo que se los puede representar como una relación parental entre dos conjuntos y no solo entre dos individuos. Este tipo de comportamiento vincular es el que nos permite considerar la noción de frente de parentesco como su principal producto colectivo.

9 Hamberger, Grange, Houseman \& Momon, 2014, pp. 568-569 (trad. pers.).

10 Definiremos una cadena como un grafo constituido por los vértices y arcos de un camino único, en el cual dos vértices poseen grado 1 , mientras el resto presenta grado 2. A su vez, entenderemos por camino a una secuencia alterna de arcos, aristas y vértices, donde cada uno de estos últimos es distinto e incidente al precedente y al siguiente. Para un tratamiento in extenso de estas definiciones y argumentos remitimos a los trabajos de Hamberger, Houseman y White (2011); Hamberger, K. (2010); White, D. (2005). 


\section{Los materiales}

Éstos, ya descritos en un trabajo anterior con motivo del análisis de la dinámica de otro frente de parentesco de la misma región se caracterizan, en general, por su parquedad informativa individual, por la pobreza de su contenido y por la ausencia de series temporales estandarizadas. Resumiremos, entonces, sus rasgos generales, remitiendo para una lectura más exhaustiva al trabajo citado (Ferreiro, 2016). En lo fundamental, nos hemos basado en la recopilación de cuatro tipos de fuentes. Por una parte, registros parroquiales del repositorio de la Prelatura de Humahuaca, de los cuales proceden actas bautismales y nupciales desde 1801 a 1890 . Se caracterizan por presentar datos acerca de los neófitos, sus progenitores, sus padrinos/madrinas y su residencia, en caso de bautismos y contrayentes, progenitores y residencia, en nupcias. Excepcionalmente se añade información sobre la generación antecedente, sobre los padrinos o testigos. En segundo caso, listados nominativos y censos provinciales, ordenados en distintas épocas, con distintos objetivos y estándares de recopilación y por distintas autoridades. En general, la información que aportan es individualmente muy escueta y de escasa utilidad. Sin embargo, si son relacionados con los anteriores y con los que describiremos luego, es posible llegar a una reconstrucción parcial, aunque satisfactoria dado el estado de la información, de algunas estructuras poblacionales locales. En general, todos estos listados y censos respetan el mismo orden lógico de registro: en primer lugar aparece un/una cabeza de familia, que tiende a ser un varón adulto -aunque se registran numerosos casos de mujeres-, al que le siguen en orden de inscripción, una mujer adulta, que casi siempre es su cónyuge, y la prole, en orden de descendencia y sexo. También se suelen incluir otros co-residentes de esas unidades domésticas, emparentados o no, a continuación del registro de la familia de orientación (de el/la) cabeza de padrón. En la mayoría de los casos, está señalado en los listados el fin de una unidad registral, que se asume como doméstica y de común convivencia. Esto ha sido contrastado luego, con datos de origen parroquial que al permitir la reconstrucción parcial de conjuntos familiares han confirmado dicha estructura de recopilación. En general y con excepciones, se ańaden algunos pocos datos referidos al oficio, residencia y edad estimada. Eventualmente, en algunos pocos listados o padrones se ańaden datos sobre condición étnica, estado de vacunación y alfabetización y en una sola muestra, de parentesco directo. Con ellos, pero con todavía menos información, añadimos los registros de empadronamientos nacionales, censos, cuyas actas individuales se encuentran para consulta en el repositorio en línea de la Iglesia de Jesucristo de los Santos de los Últimos Días. Individualmente, suelen ser los datos más parcos, pero extremadamente útiles al ser tomados en conjunto para su contrastación con la información comentada precedentemente.

Para finalizar, debemos sumar la información procedente de la recopilación oral producida por el trabajo etnográfico. Sin duda es el material individualmente más rico, aunque su información genealógica tiene la particularidad de no superar la tercera generación ascendente, con lo cual difícilmente llegamos por esta vía al principio del siglo XX, y solo para la zona septentrional del Valle Grande, esto es, Santa Ana, Caspalá, Valle Colorado. Este dato se revelará, luego, de importancia para nuestras consideraciones finales.

\section{El frente de parentesco Apaza}

Para su exhibición pública utilizaremos exclusivamente datos referidos a conjuntos patronímicos y no a individuos, a pesar de que, como lo anticipáramos, la población actual no reconoce mayor vínculo con sus antepasados más allá de la generación de sus bisabuelos.

En este conjunto se aglutinan 669 individuos organizados en torno a 65 patronímicos y con una mayoría absoluta de mujeres (352) contra 315 varones. Este volumen poblacional produjo 136 uniones, de las cuales el $86 \%$ fueron fértiles (118) generando 898 lazos filiales. El porcentaje de filiación promedio de este FP fue del 21\%, mientras que tuvieron 2,27 hijos vivos promedio al momento del registro. A la vez, presentan tasas nupciales diferenciadas para hombres (1.09) y mujeres (1.03). Esta tasa indica el promedio de uniones por cada hombre/mujer y seńala dos cosas. La primera, consistente con lo ya encontrado para el FP Mamaní, es la tendencia a evitar 
la viudez definitiva. La segunda es que, a pesar de ser menos en cantidad, los varones tendían a tener más parejas a lo largo de su vida que las mujeres. En este punto es necesario destacar que la transmisión del apellido se hizo, tendencialmente, por vía agnaticia, aunque la transmisión por vía uterina no fue en absoluto excepcional. ${ }^{11}$

Estos grupos parentales, si bien son identificados en los empadronamientos como unidades domésticas discretas en las que predomina la familia nuclear, luego de la reconstrucción de varias de esas unidades domésticas, dan claramente a entender que la agrupación habitual excedía con mucho las dimensiones de una familia nuclear; de este modo, resulta frecuente hacia mediados del siglo XIX la coexistencia de dos y hasta de tres generaciones de la misma familia en una misma residencia. ${ }^{12}$ Presentaban también, y en consonancia con esto último, una marcada tendencia a que los parientes cercanos ocuparan espacios contiguos en el territorio, tanto en los minúsculos poblados como en los puestos dispersos en los distintos pisos. La situación más emblemática de esto la constituye, para nuestro estado del conocimiento, la ocupación exclusiva del sector NE del valle de Santa Ana, denominado Piedra Grande, por parte de diversas unidades familiares del FP Apaza, algunas inclusive, de apellidos asociados, encontrándose allí, además, el reconocido hogar ancestral de este patronímico en la zona. En este sentido, sus elecciones matrimoniales parecen haber seguido una lógica similar a la descrita por Barry y Gasperoni (2008), de tender a preferir los matrimonios cercanos que no vulneren los vínculos prohibidos que, en general, se extienden a partir del tercer grado canónico.

Con el fin de ilustrar la relación interna y los pesos vinculares relativos entre los diversos patrónimos que componían el FP Apaza ofreceremos un grafo en la Figura 2 de la siguiente página.

11 Lo cual se conserva hasta hoy, institucionalizado en una categoría emic de parentesco, los "hijos del viento", esto es, todos aquellos que no tienen padre reconocido y a los que se anota y/o bautiza con el apellido materno.

12 A diferencia de lo afirmado como ideal de convivencia para los Andes por Lambert: "El ideal para cada familia nuclear completa es manejarse dentro de una unidad doméstica independiente..." (Lambert, J., 1980, p. 18).
Para su elaboración y exposición hemos recurrido al algoritmo Fruchterman-Rheingold, provisto por el programa PAJEK, que parte del principio de equilibrio de tensiones, basado en la ley de Hooke. ${ }^{13} \mathrm{~A}$ través del cálculo iterativo de los intercambios vinculares, y de una constante que regula las fuerzas de atracción y rechazo entre los nodos de la red, establece un punto de equilibrio entre las mismas. El resultado gráfico es que tales valores adquieren valor topológico disponiéndose de manera centrífuga con respecto al centro del plano bidimensional; esto es, a mayor cantidad de energía invertida en los intercambios, los nodos involucrados tenderán a ocupar el centro del gráfico; y en la medida en la que su energía disminuya, se verán radiados centrífugamente del mismo. El grosor de las líneas expresa la intensidad de los intercambios entre nodos, mientras que su diámetro está en relación directa con su grado, o participación, en tales intercambios.

La posición central y dominante, aquella que explica el nombre del FP, es ocupada, de manera esperable, por el patronímico Apaza. De manera subcentral están ubicados sus principales afinales, en particular, el patrónimo Cruz, su principal socio en el intercambio de personal conyugal. Los otros dos apellidos con los que guarda una relación particularmente intensa, a juzgar por el grosor de sus aristas, son Luere y Flores. Aun cuando ninguno de ambos presentan el mayor diámetro, esto es, la mayor actividad de intercambio matrimonial, sí, en cambio, sus presencias resultan significativas. Los primeros mencionados son vecinos tradicionales de la zona alta desde comienzos del siglo XIX; específicamente de Santa Ana, Doblonso y Caspalá, adonde los miembros del apellido Apaza se asentaron ya desde las mismas fechas y adonde aún residen. Los Luere hasta hoy conservan un estrecho grado de afinidad con Apaza en la zona de Santa Ana, adonde incluso ocupa una porción del valle de manera idéntica a como lo hacen sus principales afinales dentro del FP. Los Flores, en cambio, representan a un grupo patronímico asentado en la zona media-baja del valle, expresando los contactos nupciales que Apaza había establecido ligando las dos zonas más importantes de la cuenca del río San Francisco. Tales vínculos

13 Véase Chan, D. S. M., Chua, K. S., Leckie, C., \& Parhar, A. (2003). 


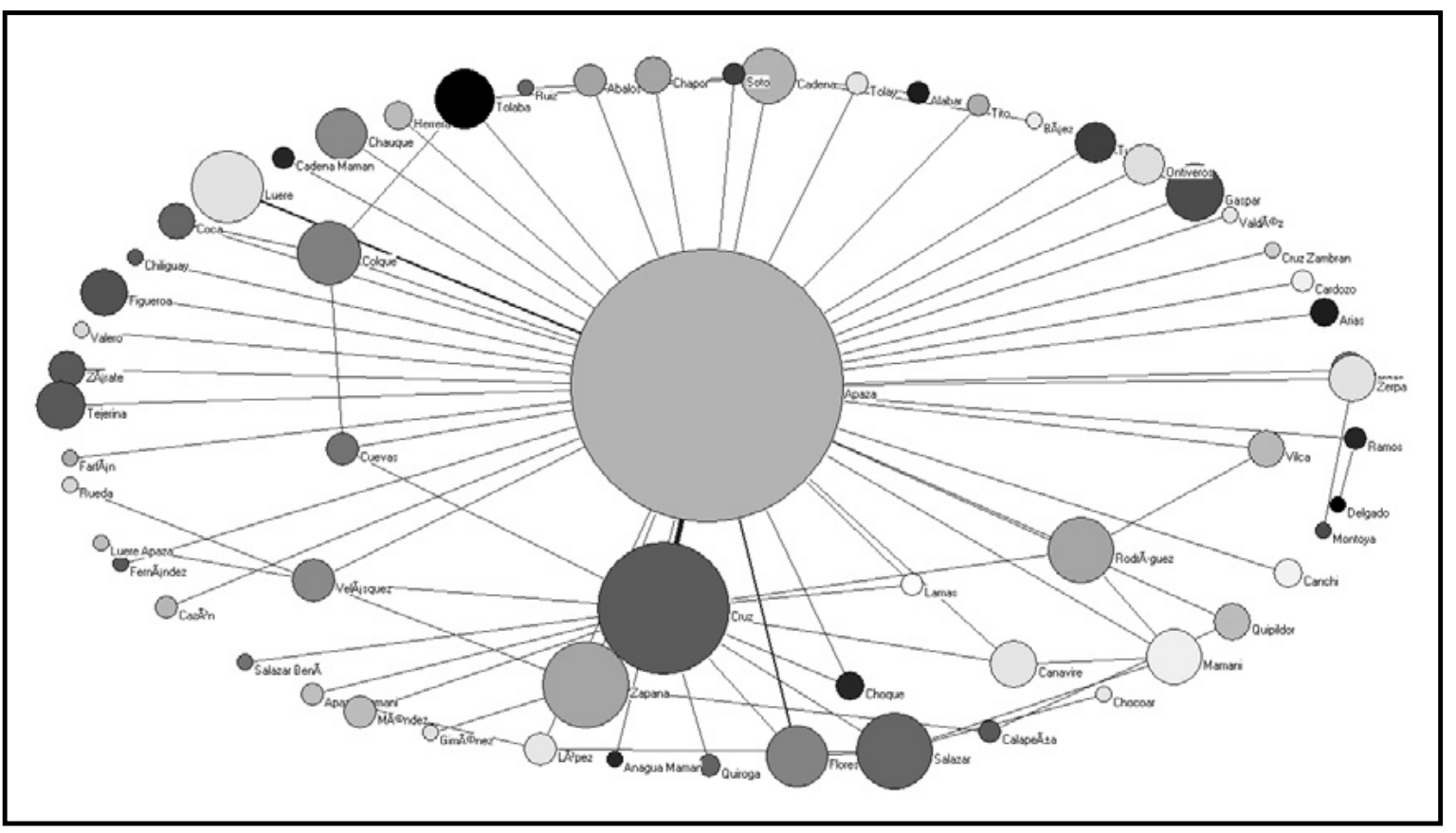

Figura 2. Composición ponderada del frente de parentesco Apaza.

son consistentes con la circunstancia específica que indica que el FP Apaza fue -y aún es-, fundamentalmente, un conjunto de familias que tendieron a situarse en la zona alta septentrional del valle, lo cual es particularmente cierto para el patronímico dominante y desde donde comenzaron a desplegarse colonizando sectores meridionales más bajos, húmedos y calurosos.

La lógica del grafo (Figura 3) es similar a la anterior, aunque en este caso, por razones expositivas utilizamos el algoritmo Spring-Embedding provisto por el graficador NetDraw, asociado al programa UCINET 6.0. Éste presenta características estructurales similares al Fruchterman-Rheingold, aunque gráficamente más claro para la presentación de una matriz de modo 2 como la que hemos cargado con estos datos. En este caso y por esta última característica se diferencian formalmente dos tipos de nodos. Unos, cuadrados, expresan las localidades de donde provienen los diversos patrónimos que componen el FP. Los otros, globulares, representan a esos mismos apellidos.

Como se puede observar con claridad, la zona central y hacia la cual convergen, o desde la cual se irradian las líneas de mayor intensidad, está ocupada por el nodo Apaza. Lo que nos interesa resaltar analíticamente en este caso es que las líneas de mayor intensidad desde el centro están dirigidas hacia Caspalá, La Candelaria, Valle Grande y Santa Ana, en ese orden. Esa es, precisamente, la travesía que recorrieron los miembros del patrónimo Apaza desde sus residencias en las tierras altas del norte del valle (Caspalá y Santa Ana), atravesando su zona central, de yungas y contacto con las salidas a las tierras bajas (Valle Grande) y dirigiéndose hacia fuera del valle, a su vecino meridional, el valle de La Candelaria, adonde se fueron asentando ya desde la década de 1830 en adelante, posiblemente siguiendo un circuito de trashumancia pastoril. En este punto es destacable que, mientras el FP Mamaní -cuya genealogía fuese expuesta en un trabajo anterior-, se va instalando siguiendo la cuenca del río Valle Grande-San Francisco hacia su salida a Calilegua, en las tierras bajas orientales del piedemonte chaqueño, Apaza hace exactamente lo contrario, comienza a instalarse en un valle bajo meridional ubicado al $\mathrm{SO}$, y que tiene salida al sector meridional de la Quebrada de Humahuaca. También es posible observar que, a la nutrida vinculación que dentro del FP el apellido Apaza establece con prácticamente todas las locali- 


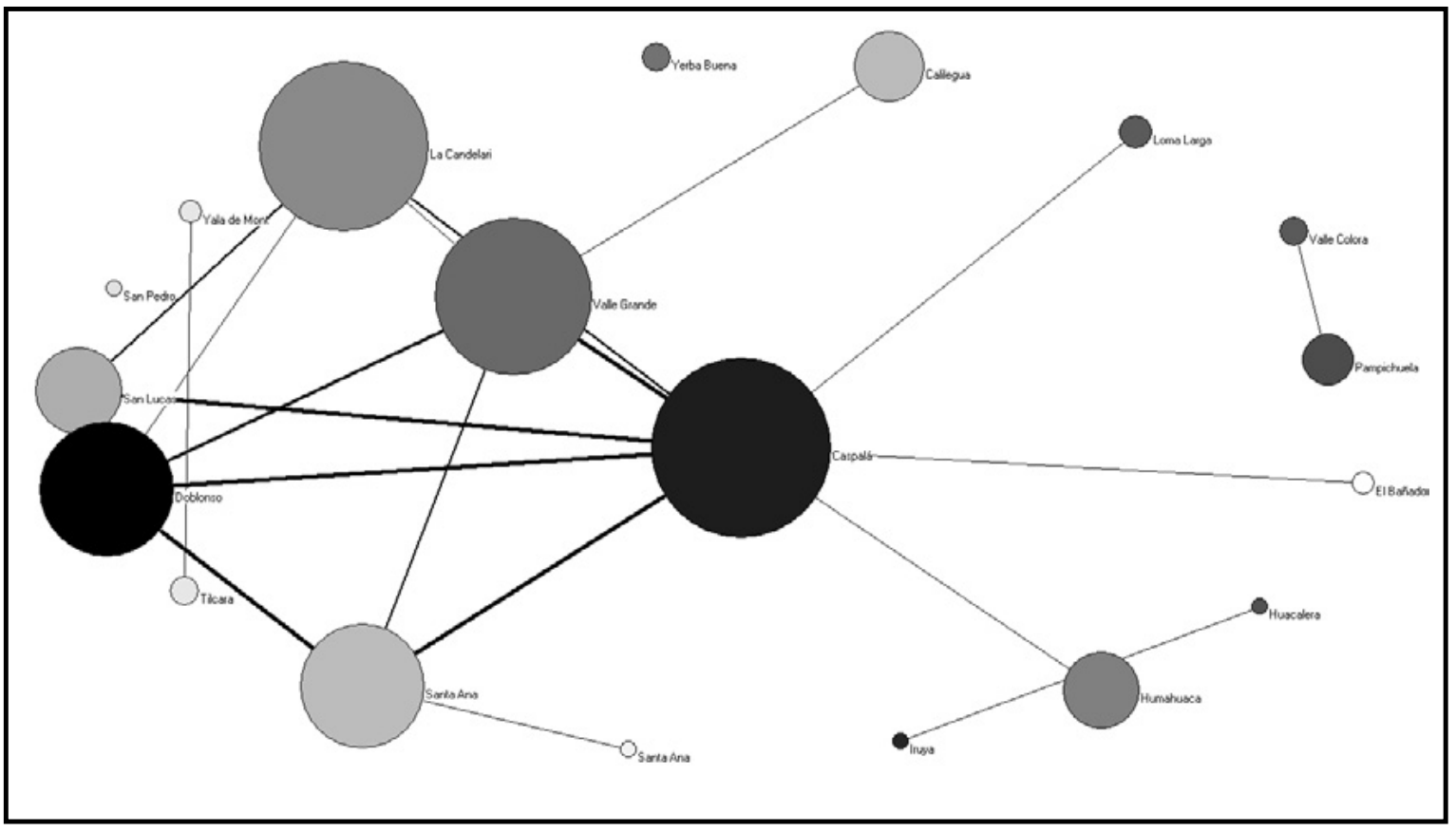

Figura 3. Origen y relación interpatronímica ponderada del frente de parentesco Apaza.

dades del valle (salvo Yerba Buena), se corresponde una significativa ausencia de vínculos con apellidos de poblaciones externas a él (Huacalera, Iruya, San Pedro, El Bañado). Tampoco resulta casual la ubicación central de su principal afinal, Cruz, cuyos miembros se encuentran multilocalizados en todas las regiones y pisos del valle.

Para comenzar a discutir algunos aspectos de los comportamientos matrimoniales que estos grupos desarrollaron, es necesario primero explorar algunos límites estructurales de la muestra. Sabemos que la transmisión del apellido es tendencialmente agnaticia, que los padrones y listados son encabezados habitualmente por varones, aunque el parentesco andino tiende a ser bilateral, lo cual es constatable en la actualidad y razonablemente suponemos que pudo ser así en el siglo XIX. ${ }^{14}$ Por lo tanto, debemos precavernos de que la información recopilada, en última instancia la memoria que queda del ordenamiento y el registro familiar, no esté sesgada por el propio sistema de parentesco y por su ideología, de modo que induzca una preferencia cultural allí donde solo hay una necesidad demográfica. Con este objetivo recurrimos a una herramienta provista

14 Lambert, J., 1980. por el programa PUCK que permite, aun en casos de pobreza relativa de información como el que aquí presentamos, evaluar su calidad como fuente a partir del análisis de la composición de la "memoria genealógica” (Barry y Gasperoni, 2008). Por esta entenderemos no solo aquello que un individuo recuerda acerca de sus ancestros, sino y sobre todo tomando en cuenta la naturaleza de nuestras fuentes, lo que el sistema de recopilación, la Iglesia y el Estado fundamentalmente, registran de manera institucionalizada.

El primer aspecto a tener en cuenta es que esta sociedad, con las características generales arriba descritas, exhibe una mayoría demográfica femenina. El segundo, esperable por lo demás, es que las recopilaciones escritas han retenido una proporción minúscula de los lazos genealógicos antecedentes. Sobre un máximo de tres generaciones ascendentes registradas en las fuentes escritas, encontramos que para un total de 418 parientes recordados, 222 lo son por vía femenina, a diferencia de lo descrito para otras regiones andinas, como la comunidad de Marcapata en Cusco, donde N. Sato (1981) encuentra que la genealogía agnaticia es la más recordada, mientras que, como aquí, la uterina no supera la tercera generación. 


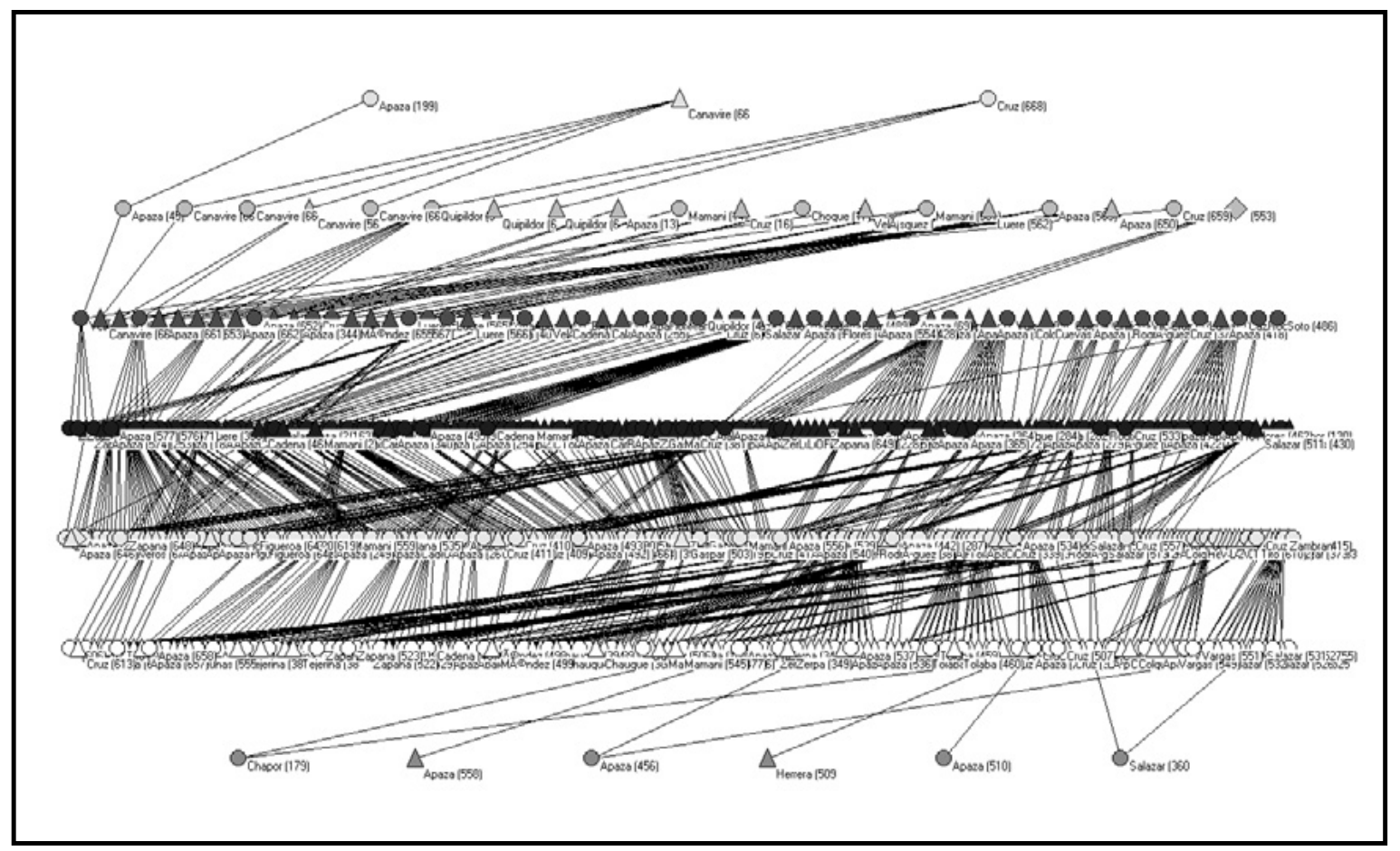

Figura 4. Relación entre generaciones y memoria genealógica del frente de parentesco Apaza.

El grafo que ofrecemos arriba (Figura 4) ilustra la relación entre generaciones y memoria genealógica.

En el grafo de referencia la información está ordenada generacionalmente. La fila superior representa los apellidos cuya descendencia alcanza, mediante la reconstrucción genealógica, hasta cinco generaciones descendentes. La fila inferior, por el contrario, representa a aquellos apellidos integrantes del FP que únicamente registran una sola referencia antecedente, esto es, solamente se les asocia el registro de la generación de los progenitores. Nuestro interés reside en la actividad desarrollada entre las filas segunda a cuarta contando desde abajo. Éstas representan el grueso de la información de las fuentes históricas escritas. Entre ellas, en particular entre la segunda y la tercera, y entre la tercera y la cuarta, se concentran los lazos que indican vinculación intergeneracional explícita. Esto es, las tres generaciones recordadas por la memoria escrita en las fuentes que comentábamos en el párrafo antecedente y que implican el registro expreso hasta la generación de los bisabuelos. De la fila cuarta a la sexta, los vínculos intergeneracionales son el producto de una reconstrucción analítica. Los símbolos utilizados respetan la convención antropológica habitual, los triángulos identifican individuos de género masculino, y los círculos, individuos femeninos, mientras los rombos representan parientes genéricos.

De las dos primeras generaciones antecedentes recordadas, o sea, los vínculos establecidos entre las filas segunda a cuarta comenzando desde abajo, el personaje con mayor presencia documental es el XFH(H) o FFM, esto es, el padre del padre de la madre de un ego (femenino o masculino). El segundo personaje más registrado es la XFH (F) -MFM-, la madre del padre de la madre de un ego (masculino o femenino). Para la memoria agnaticia este personaje femenino es también el más recordado. El tercero es el padre de la madre de la madre -XFF (H) o FMM-. Más notablemente aún, en los recientes trabajos etnográficos se pudo constatar que no solo la memoria oral está fijada en la tercera generación ascendente, que únicamente se supera en casos absolutamente excepcionales, sino que también los parientes más recordados suelen ser los que provienen de la vía uterina. Llevados a una generación más, la cuarta que, como dijimos, ha sido objeto de reconstrucción vía fuentes-, pudimos constatar que solo se recuerda 
a los parientes maternos. Por lo tanto tratándose de datos escasos, éstos no son un reflejo directo de la transmisión del apellido. Antes bien, lo que parece subrayarse atendiendo a los grados de parentesco referidos, es la bilateralidad y la ausencia significativa de una idea de linaje o pedigree, tan obsesivamente presente en el pasado de la élite colonial provincial.

Estas son algunas de las condiciones, entonces, sobre las que se establecieron los lazos matrimoniales posteriores y los que, de una manera o de otra, influyeron en la presencia de ciertos tipos de matrimonios.

Los pocos circuitos matrimoniales que han podido ser reconocidos más allá de toda duda establecen con claridad que dos de ellos fueron entre individuos emparentados en un grado 2 de profundidad genealógica, WFZ según la notación tradicional, H.FH()F en la notación posicional, esto es, el casamiento con la hermana del padre de la esposa de ego; BWZ o H()H.F()F, o sea, el casamiento con la tía política. En ambos casos fueron dos parejas por circuito. En este último caso, los individuos involucrados provenían de grupos familiares asentados en Doblonso y Caspalá, valles vecinos e interconectados que servían, el uno de terreno de cultivo y el otro de área de pastoreo para la zona septentrional de Valle Grande. En el primero, en cambio, provenían una de un grupo familiar asentado en Caspalá, y el otro en Santa Ana; esto es, los poblados en los que más se asentaron los miembros del FP Apaza y que más contacto tuvieron entre sí históricamente. Todavía hoy la travesía para unir ambos valles se realiza a través de Doblonso, configurando, entonces, un circuito no solo matrimonial, sino productivo y geográfico que tiene al casamiento cercano como dispositivo sociocultural privilegiado de reproducción social.

Los otros seis circuitos ponen de manifiesto aún más la característica endogámica, y casi levirática, presente. Éstos involucraron a los siguientes tipos: WFFWD o H.FH(H).(F)F, que, a la vez eran ya WFMHD o H.FH(F).(H)F, esto es, el casamiento con la tía de su esposa. Notoriamente, esta pareja se constituyó como el núcleo conyugal desde el cual comenzó a desplegarse el evangelismo en la zona norte de Valle Grande, con epicentro en Santa Ana. El otro circuito fueron dos casamientos de tipo MHSWZ o H(F).(H)H.F()F, que ya implicaban BWMHD o H()H.F(F).(H)F. ${ }^{15}$ En ambos casos se trató de matrimonios que enlazaban conjuntos familiares también de Doblonso y Caspalá, reforzando así su carácter de dispositivos socioculturales de la endogamia. Estos últimos dos tipos también fueron parte del arsenal estratégico matrimonial de la élite colonial jujeña y funcionaron, en ese caso, como dispositivos para retener y para adquirir patrimonio fundiario en el sentido que le diese P. Lamaison (1977), cuando caracterizó esta dinámica como “endogamia patrimonial". ${ }^{16}$ Precisamente, el tronco familiar involucrado en esta operación -Goyecheaera el propietario de la enorme estancia en la que estuvo incluida, durante el siglo XVII y buena parte del XVIII, la zona de Valle Grande, donde ańos después se reiterarían estos tipos de matrimonios.

Aquí debemos destacar que la zona se caracterizó, de acuerdo a diversos autores, históricamente y aún lo hace, por presentar los mayores índices de endogamia de la provincia; también es un tópico actual entre los pobladores del departamento. ${ }^{17} \mathrm{~A}$ este fenómeno hemos optado por diferenciarlo internamente en, por lo menos, tres configuraciones distintas. Por una parte, lo que comúnmente se denomina endogamia y que implica simplemente un casamiento cercano, por ejemplo, entre vecinos de pueblo, localidad, etcétera, no necesaria ni recordadamente emparentado y al que denominamos endogamia de localidad. Por otro, el efectivo casamiento entre parientes en algún grado, esto es, la endogamia estricta. Finalmente, reconocemos un tercer tipo de endogamia, que es el lazo creado entre miembros del mismo apellido y cuyo pasado común no se recuerda, o no se considera. Si tomamos en cuenta los tres tipos, la endogamia durante la segunda mitad del siglo XIX alcanzó el $98 \%$ de la población del

15 Como afirman Hamberger, Houseman y Grange, “... un corpus con una muy baja profundidad genealógica difícilmente puede ser utilizado para revelar la ausencia de matrimonios entre consanguíneos...” (Hamberger, Houseman y Grange, 2009, p. 17).

16 Esta forma particular de endogamia está destinada a bloquear la circulación de bienes entre troncos o linajes, impidiendo así la concreción de la lógica matrimonial, que la habilita. Véase Héritier (1980).

17 Véase Teruel y Gil Montero (1996); Belli y Slavutsky (1996); Belli (2004); Fernández (2013). 


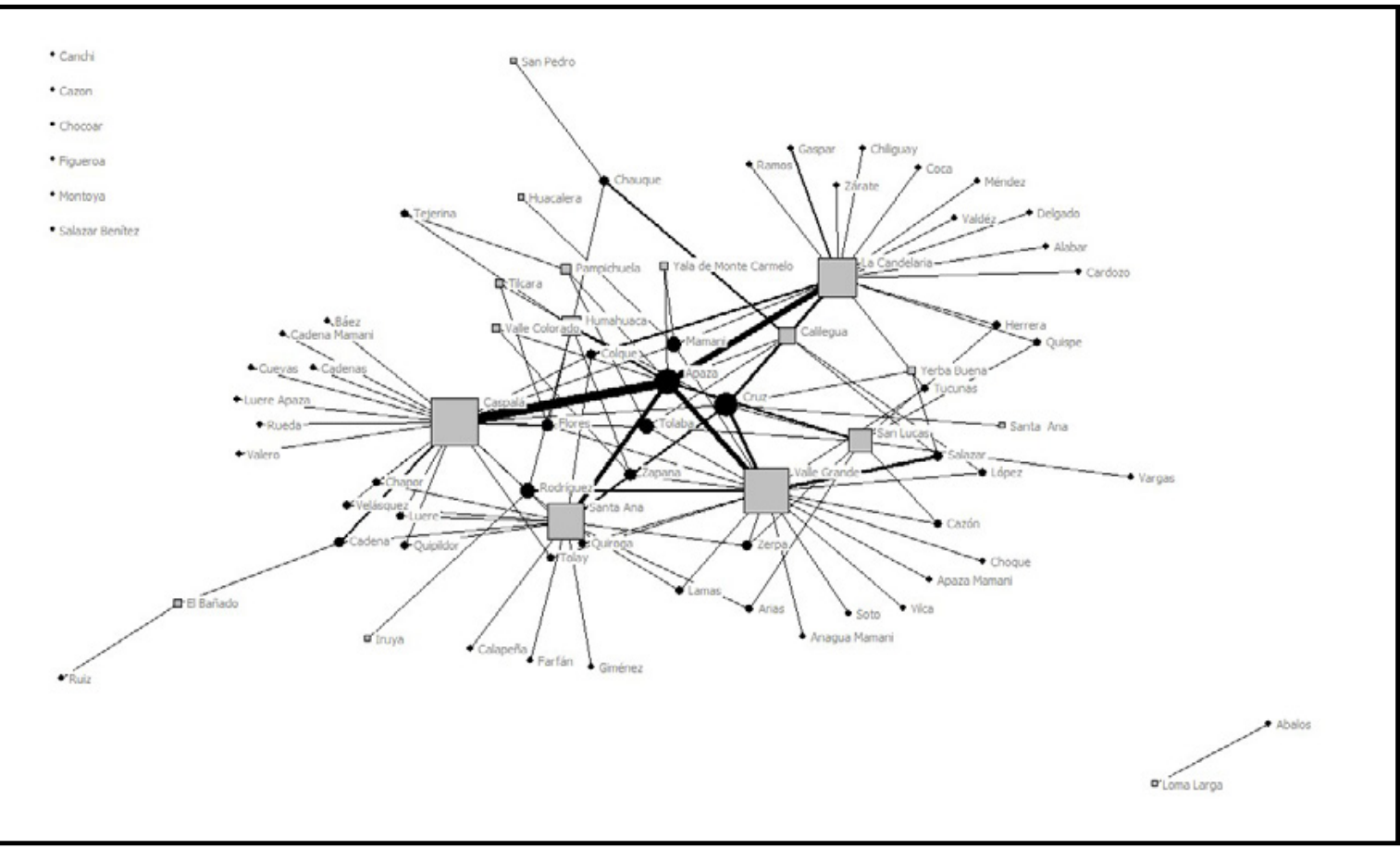

Figura 5. Matrimonios por localidad, frente de parentesco Apaza.

departamento Valle Grande, situación análoga a la que ocurrió entre la élite colonial y luego tempranorepublicana de Jujuy. ${ }^{18}$ En este sentido, señalamos que entre los matrimonios realizados dentro del FP solo los contraídos entre Apaza y Cruz son más numerosos que los que se establecieron al interior del patronímico Apaza.

En este grafo (Figura 5) nuevamente recurrimos al algoritmo Fruchterman-Rheingold comentado páginas atrás. En este caso, independientemente de los apellidos, lo que queremos mostrar es la relación entre las localidades de residencia habitual y/u origen, con los intercambios matrimoniales dentro del FP Apaza. De este modo, los nodos representan las poblaciones; sus diámetros, el volumen del personal matrimonial involucrado y el grosor de sus líneas, la intensidad de los intercambios entre poblados.

18 Sobre los Goyechea, propietarios coloniales del territorio vallegrandino, véase Paz, G. (1997). Estos valores de endogamia, muy superiores a los que se conocen para el resto de la provincia, son similares a los que Sara Lund Skar (1998) encontraba, para fines de la década del setenta, en el norte de Apurímac, sierra sur peruana.
Se observa fácilmente el papel central que le cupo a Caspalá, la población más antigua y productiva de la zona alta en dicha dinámica y su conexión histórica con la zona alta de la Quebrada de Humahuaca -tal cual se constata en el grafo, ya que los matrimonios contraídos con gente de esta última región solo se produjeron a través de enlaces con caspaleños/as-. A partir de ese centro se identifican dos polígonos que cubren la casi totalidad del territorio de las cuencas de los ríos Santa Ana, Caspalá, Hornos y San Francisco -los principales del valle-. Dicho polígono tiene a Santa Ana, Doblonso y Valle Grande como referencias con las cuales se estableció un intercambio particularmente intenso; esto es, la zona alta y la cuenca media-baja, salida obligada a las tierras bajas del SE y valles meridionales. A su vez, ese polígono se amplía, aunque con intensidad debilitada, abarcando San Lucas y La Candelaria. El primero de ellos es un valle que aún hoy sirve de conexión, de puerta de acceso al sector medio-norte de la Quebrada de Humahuaca a través de la travesía Molulo/ Durazno-Tilcara. La Candelaria, valle bajo meridional, es el último reducto adonde se instaló personal de este FP. A diferencia de otros FP, como Mamaní, Apaza colonizó intensamente esa zona, en lugar de 
buscar la salida del valle siguiendo la baja cuenca del San Francisco hacia el SE, a la salida por Calilegua hacia las tierras del ramal, el piedemonte oriental y las tierras bajas colindantes con el Chaco. Esta situación se observa con claridad al ver no solo la excentricidad, sino también el diámetro y la intensidad de los vínculos con Calilegua, que se conecta únicamente con el polígono principal a través del eje articulador de Valle Grande y de San Pedro, en total desconexión del sector nuclear. Notoriamente, solo San Lucas, en el trayecto entre las tierras altas y las bajas, tiene una intensidad de vínculo comparable a Caspalá con Candelaria. Las otras conexiones de este valle meridional son mucho más débiles, con Doblonso - tierras de pastoreo de la zona alta- y con Valle Grande. Esto sugiere que el paso preferido por los grupos que compusieron este FP se trasladó hacia el sur a través del borde occidental de la serranía; esto es, desde Caspalá a San Lucas/Santa Bárbara/ Loma Larga -eventualmente tocando Pampichuela, que aparece presente pero desconectado-, hacia La Candelaria y sorteando parcialmente Valle Grande. En otras palabras, La Candelaria fue colonizado, en el contexto del desplazamiento del FP Apaza, por los grupos provenientes de Caspalá. Tal migración colectiva parece haber comenzado antes de la década de 1830 y finalizado hacia la década de 1860, y una de sus razones pudo haber sido el estado de guerra civil permanente que vivió la región en ese período. La composición de las unidades domésticas provistas por los censos y padrones de 1839 y 1859 parecen insinuarlo. Para la primera de estas fechas, las unidades que nuclean a personal de este FP son nueve sobre un total de 64 reconocidas, esto es, una tasa del $0,14 .{ }^{19}$ De estas unidades domésticas, la gran mayoría -seis sobre tres- estaban encabezadas por una mujer adulta. Dos de estas unidades permiten reconocer una familia nuclear, precisamente las encabezadas por varones; mientras que otras dos son caracterizables como familias compuestas, una de ellas como familia extensa y finalmente tres cuya composición no indica conyugalidad, sino convivencia entre parientes afines o siblings, sin sus pa-

19 Dicha tasa consiste en un cálculo muy simple, la cantidad de unidades domésticas del FP divididas por la cantidad total de ellas reconocidas en el censo, y permiten utilizarla como base de comparación entre los diversos listados, censos y padrones donde se reconocen tales unidades. rejas, pero con sus respectivas descendencias. ${ }^{20} \mathrm{La}$ significativa ausencia relativa de cabezas de padrón varones sugiere el contexto bélico antes aludido. Para el censo siguiente, realizado en 1859, la tasa no se había modificado, continúa siendo de 0,14 , aunque expresando una relación de 13 unidades domésticas censales sobre 89. A diferencia del anterior, para esta oportunidad, de esas unidades domésticas solo una está encabezada por una mujer. Las familias nucleares fueron tres; las reconocidas como extensas resultaron la amplia mayoría, ocho, y tanto las compuestas como las unidades de convivientes no conyugales fueron una cada una. Esto nos sugiere la continuación del flujo migratorio, representado por la cantidad de familias extensas, pero estabilizándose en cuanto a su composición y encabezamiento habituales en el resto de la zona para la época.

Doblonso, por su parte, denominado Lonlonso en las fuentes del temprano siglo XIX, acogió parte del contingente del FP. Para el censo de 1852, sobre 41 unidades domésticas censadas que pudieron ser reconstituidas -hoy no hay más de seis, de las cuales solo están habitadas permanentemente dos-, siete albergaron a personal Apaza y afinales, lo cual da una tasa de 0,17 , superior a la exhibida por La Candelaria. Seis de esas unidades domésticas estuvieron encabezadas por un varón; cinco se caracterizaron como familias nucleares y solamente dos como extensas.

En la misma recopilación, Caspalá, el centro de operaciones del FP, sobre 37 unidades domésticas censales reconstituidas, siete -prácticamente 0,19 de tasa y la más alta de todo Valle Grande- eran ocupadas por familiares de ese conjunto. En su totalidad encabezadas por un varón adulto y únicamente una familia nuclear contra tres que caracterizamos como compuesta y otras tantas extensas. Pocos años después, en 1864, estas composiciones han variado un poco. La incidencia del FP en el conjunto es me-

20 Entenderemos por familia nuclear una unidad constituida por una pareja conyugal y, eventualmente, su descendencia soltera. Por familia compuesta identificaremos a una unidad en la que son censadas conviviendo más de una pareja conyugal, con o sin su descendencia. Una familia extensa significará, en este caso, un/a cabeza de padrón con o sin su pareja conyugal, más su descendencia y/o allegados/criados/entenados/as con o sin descendencia. 
nor, pasando a 0,17 de tasa, 7/41 unidades domésticas. De éstas, cinco eran encabezadas por un varón adulto y dos por una mujer. Dos de esas unidades pueden considerarse nucleares, mientras que otras tantas eran extensas y tres albergaban variados conjuntos de convivientes no conyugales. Dos de ellas pertenecían al apellido Apaza y estaban compuestas por miembros lineales y colaterales de tres generaciones distintas encabezadas por mujeres. La última estaba constituida por un viudo, parte de su descendencia soltera, algunos descendientes de ésta y colaterales.

\section{Algunas reflexiones finales}

La fuerte presencia de vínculos endogámicos nos lleva a pensar en algunas paradojas significativas entre los dispositivos utilizados por esta población de campesinos indígenas durante el siglo XIX y parte del XX, y aquellos utilizados por la élite colonial hispanocriolla. En esta última, el sentido de la genealogía y el pedigree llevó a algunos de sus miembros a registrar por escrito la larga saga familiar del fundador de la ciudad, sus descendientes y afinales, aquellos a través de los cuales terminó discurriendo el patrimonio de los Argañarás y Murguía, linaje en el cual se insertaron los Goyechea. La memoria y la endogamia como estrategia les sirvieron como argumentos para retardar la fuga del patrimonio familiar hacia otros linajes, tal como comentamos que actúa la denominada "endogamia patrimonial". En este caso, la memoria como pedigree ignoró estratégica y sistemáticamente las miscegenaciones, numerosas, comprobadas y con descendencia en suelo jujeño hasta el día de hoy, en función de la búsqueda de, sobre todo, varones vascos primero y europeos lato sensu -y sus descendientesdespués. Precisamente, la metodología genealógica tradicional está diseñada con esos fines; sus dificultades comienzan al intentar incorporar datos contradictorios, líneas paralelas, etcétera.

En el caso de los campesinos indios del valle, la memoria también fue objeto de olvidos - ¿selectivos?En una población estabilizada demográficamente durante varios siglos, con casi nulo aporte migratorio y un alto grado de aislamiento físico provocado por lo abrupto de su territorio, el no llegar a recordar más de tres generaciones ascendentes no parece solo una cuestión de mero olvido. Héritier primero y Barry y Gasperoni luego han comentado y analizado el papel de la tercera generación ascendente en el establecimiento del límite del tabú y el comienzo de lo que la primera autora denominase "comunidad lejana”, el sector cercano pero permitido, de parientes matrimoniables y, eventualmente, preferibles.

Desde los primeros registros que se guardan a principios del siglo XIX hasta la actualidad, la memoria pública no puede superar esas tres generaciones $\mathrm{y}$, por lo tanto, la genealogía o el pedigree no tienen mucho espacio ni pueden ofrecer demasiado interés. Una de sus consecuencias es que la altísima tasa de endogamia que se sabe que existe -bajo alguna de las formas antes comentadas- queda invisibilizada a partir de, precisamente, la tercera generación. Parte de ese problema se cuela en la preocupación que algunos pobladores muestran actualmente por lo que llaman sin especificar "el casamiento entre parientes" o las dificultades que padecen las nuevas generaciones para establecer vínculos románticos o sexuales con coetános que no compartan el mismo apellido. En la actualidad esto ha recibido un poderoso impulso ideológico de la mano de los creyentes evangélicos, quienes han establecido, en líneas generales, un neto corte con el pasado a partir del renacimiento que implica el bautismo, notoriamente activo en parte del FP Apaza.

Aunque, desde luego, tan pocos casos registrados no permiten concluir nada, sí, en cambio, sugieren perspectivas de trabajo. En esta línea puede pensarse que uno de los efectos posibles de la endogamia, en cualquiera de sus formas, parece ser un uso especular negativo al que hizo (y hace) la élite, la negación lógica de la genealogía a través del olvido selectivo. Justamente a través de esto último es posible ver cómo dos sectores sociales diferenciados en el tiempo y en su posición estructural -aunque ocupando territorios contiguos- hicieron uso diverso de principios y materiales muy similares, la danza performática que comentábamos al principio del trabajo.

Por su parte, las tendencias observadas en los circuitos matrimoniales acompańaron el despliegue espacial actuando como auténticos dispositivos que componían, en su danza, una pauta endogámica 
con una orientación específica hacia la contigüidad territorial. Por su parte, la composición familiar, al menos la del contingente que ocupó el meridional valle de La Candelaria, parece haber acompañado, a su vez, los tiempos que corrían organizando a parte de esa población de acuerdo a criterios que no parecen haberse regido exclusivamente por la descendencia o filiación, sino también y fundamentalmente por la necesidad coyuntural y, nuevamente, la vecindad física.

\section{Agradecimientos}

Las investigaciones - de las cuales este trabajo es un producto- fueron realizadas con subsidios a la investigación de SECTER-UNJu y del PID, "El sur andino en la encrucijada temprano colonial: prácticas, materialidades y representaciones. Continuidad y resignificación en Charcas y Tucumán, siglos XVI-XVII", dirigida por la Dra. A. M. Presta, CONICET-Instituto Emilio Ravignani-UBA. A mi familia, y a los integrantes de la familia Apaza de Santa Ana, Valle Grande. A mis compañeros de trabajo de campo, Federico Fernández, Federico Sona Sombory y Saúl Tejerina.

\section{Referencias citadas}

Barry, L., \& Gasperoni, M. (2008). "L'oubli des origines: amnésie et information généalogiques en histoire et en ethnologie“.En Annales de démographie historique, 2, 53104. Société de Démographie Historique.

Barry, L. (2004). "Historique et spécificités techniques du programme Genos”. Ecole Collecte et traitement des données de parenté.

Bateson, G. (1979). Espiritu y Naturaleza. Buenos Aires: Amorrortu.

Belli, E., Slavutsky, R. (1996). La Modernidad Agrietada. Los procesos politicos en Jujuy. Buenos Aires: Instituto Interdisciplinario Tilcara, FFyL, UBA.

Belli, E. (2004). Algunas implicancias de las politicas de ajuste y modernización en Valle Grande. Provincia de Jujuy, Tesis doctoral, FFyL, UBA. Buenos Aires. En prensa.
Chan, D. S. M., Chua, K. S., Leckie, C., \& Parhar, A. (2003). Visualisation of power-law network topologies. In Networks, 2003. ICON2003. The 11th IEEE International Conference on, 69-74. IEEE

De Feo, C. y Fernández, A. (1998). "Una aproximación al periodo Tardío en la arqueología de Valle Grande (Jujuy)”. En Jerez, O. Teruel A (Comps.). Pasado y Presente de un mundo postergado. Edit. Universidad Nacional de Jujuy.

Evans-Pritchard, E. E. (1982). Antropología Social, Buenos Aires: Nueva Visión.

Fernández, F. (2013). ENTRAMADOS. El fútboly las identidades sociales en los valles orientales de Jujuy. Ediunju, S. S. de Jujuy.

Ferrand, A. (2003). "Las comunidades locales como estructuras meso" Redes. Revista hispana para el análisis de redes, vol. 3-4 http: //revista-redes.rediris.es

Ferreiro, J. P. (1994). "El Chaco en los Andes. Churumatas, Paypayas, Yalas y Ocloyas en la etnografía del oriente jujeño”, Población y Sociedad, 2. Tucumán.

Ferreiro, J. P. (2013). "Compadrazgo y dinámica reticular en Valle Grande, Jujuy”. En Sendón, P. F., y Villar, D. (Eds.). Al pie de los Andes. Estudios de etnología, arqueología e historia (pp. 109- 135). Cochabamba: ILAMIS-CIHA-Itinerarios.

Ferreiro, J. P. (2014). “Los apellidos, la organización familiar y los circuitos productivos como determinantes de la cotidianeidad en el oriente jujeño, siglo XIX”. En Ghirardi, M. (Coord.). Territorios de lo cotidiano Siglos XVI-XX. Del antiguo virreinato del Perú a la Argentina contemporánea (pp. 215-229). Rosario: PROHISTORIA Ediciones. ISBN 978-987-1855-83-4.

Ferreiro, J. P. (2016). "De barro somos... Ciclos familiares y genealogía en el poblamiento del oriente jujeño del XIX”, Surandino Monográfico (pp. 23-44), vol. 5, Buenos Aires: PROHAL, FFyL-UBA. ISSN 1851-9091.

Ferreiro, J. P., y Fernández, F. (2013). "Nupcialidad, compadrazgo y endogamia en las Yungas de Jujuy (Noroeste de Argentina) durante la primera mitad del siglo XIX", Caravelle. Cahiers du monde hispanique et luso-brésilien (pp. 101, 21-57), Dec. 2013, IPEAT, Toulouse. ISSN 1147-6753; ISBN 978-2-8107-0289-3. 
Fumagalli, M. (1995). "Vinculaciones transversales en el periodo de Desarrollo Regionales entre los valles orientales y el sector meridional de la Quebrada de Humahuaca”, Cuadernos, 5, Facultad de Humanidades y Ciencias Sociales. Jujuy: UNJu.

Hamberger, K. (2010). Espaces de la parenté. L'Homme Revue française d'anthropologie, 451-468. École des Hautes Études en Sciences Sociales. <hal-00661889>.

Hamberger, K., Houseman, M., \& Grange, C. (2009). "La parenté radiographiée", L’homme, 191(3), 107-137.

Hamberger, K., Houseman, M., White, D. R. (2011). “Kinship Network Analysis”. En Scott, J., \& Carrington, P. J. (Eds.). The Sage Handbook of Social Network Analysis, Sage Publications. <halshs-00658667>

Hamberger, K., Grange, C., Houseman, M., \& Momon, C. (2014). Scanning for patterns of relationship: analyzing kinship and marriage networks with Puck 2.0. The History of the Family, 19(4), 568-569, DOI: 10.1080/1081602X.2014.892436

Héritier, F. (1980). L'exercise de la parenté. Paris: GallimardLe Seuil.

Lamaison, P. (1977). Parenté, Patrimoine et Stratégies matrimoniales sur ordinateur. Une paroisse du Haut-Guévaudan du XVIIè. au début du XIXè siècle. Thèse de 3è. Cycle, Université René Descartes, Paris.

Lambert, J. (1980). "Bilateralidad en los Andes”. En Mayer, E., y Bolton, R. Parentesco y matrimonio en los Andes (pp.11-54). Lima: Pontificia Universidad Católica del Perú.

Lévi, G. (1990). La herencia inmaterial. La historia de un exorcista piamontés del siglo XVII. Madrid: Nerea.

Lévi-Strauss, C. (1969) 1949 Las estructuras elementales del parentesco. Buenos Aires: Paidós.

Murra, J. V. (1975). Formaciones económicas y políticas del mundo andino. Lima: Instituto de Estudios Peruanos.

Nielsen, A. (1989). La ocupación indigena del territorio Humahuaca oriental durante los periodos de desarrollos regionales e Inca, Tesis doctoral, Universidad Nacional de Córdoba, Ms.
Nielsen, A. (2003). "Por las rutas del Zenta: evidencias directas del tráfico prehispánico entre Humahuaca y las Yungas”. En Ortiz, G., y Ventura, B. (Comps.). La mitad verde del mundo andino. Investigaciones arqueológicas en la vertiente oriental de los Andes y las tierras bajas de Bolivia y Argentina. Jujuy: UNJU.

Paz, G. (1997). "Familia, linaje y red de parientes: la elite de Jujuy en el siglo XVIII", Andes, 8.

Salas, A. M. (1992). Los indígenas de la quebrada de Humahuaca. El descubrimiento del territorio (Caps. II y III de El antigal de Ciénaga Grande). San Salvador de Jujuy: Ed. Univ. Nac. de Jujuy.

Sánchez, S., y Sica, G. (1990). "La frontera oriental de Humahuaca y sus relaciones con el Chaco”. En Boletín de Instituto Francés de Estudios Andinos, 19(2), Perú.

Sato, N. (1981). "El concepto de ayllu y Qata/Q'acun: un estudio de la familia, el parentesco y el ayllu”. En Masuda, S. (Ed.). Estudios etnográficos del Perú meridional (pp. 139-174). Tokio: Universidad de Tokio.

Skar, S. L. (1998). "El final de la endogamia: el parentesco andino en terreno abierto". En Arnold, D. Y. (Comp.). Gente de carne y hueso. Las tramas de parentesco en los Andes (pp. 99-114). La Paz: ILCA-CIASE.

Teruel, A. y Gil Montero, R. (1996). “Trabajo familiar y producción de textiles en las tierras altas de la provincia de Jujuy. Mediados del siglo XIX”, Revista Andina, 1, año 14, julio, Lima.

White, D. (2005). “Teoría de la cohesión circular en el matrimonio y las redes sociales", Empiria. Revista de metodologia de Ciencias Sociales, 10, julio-diciembre, 37-69, ISSN 1139-5737.

\section{Fuentes documentales}

\section{Archivo Histórico de la Provincia de Jujuy}

Expediente no 467 -C- 1905, Antecedentes sobre el camino del pueblo de Valle Grande a la estación San Lorenzo. Sección Expedientes-Archivo Histórico de la Provincia de Jujuy. 
Padrón de población de la hacienda de Ledesma, Vice parroquia de La Candelaria, hacienda de San Lorenzo y de la reducción al Lavayén, 1839.

Padrón del partido de Valle Grande, Caja 2 - Valle Grande - 1859 (1852).

"Catastros levantados en 1883. Dptos. Capital, Perico del Carmen, San Antonio, San Pedro, Ledesma”.

1843: Censo Curato de Río Negro.

1851: Estadisticas y censos. Padrones de Yavi, Rinconada, Santa Catalina, Cochinoca, Rio Negro, Tumbaya, Valle Grande, Capital, Curato del Sudy Poniente.

1859: Censos habitantes Valle Grande y Cochinoca.

1864: Censos departamentos Valle Grande, Rinconada, Humahuaca y Yavi.

\section{Archivo de la Prelatura de Humahuaca}

Libro de bautismos 1827 a 1843, Libro H, No 1, (Partida de oleos y bautismos administrados en la capilla de Lonlonzo, ayuda de parroquia de Humahuaca año de 1827); Libro de Bautismos. 1849-1888. no II. Humahuaca y Anejos; Libro 2 de Bautismos Anejos 1823 a 1827 (J-Bautismos 18231827). - (1022 actas)

\section{Archivo de Tribunales de la Provincia de Jujuy} Copia de merced de Caspalá a Martín de Goyechea. Año 1698, Expdte. 1645 (1776). 